\title{
The Design Method of "Semiosis" in Interior Furnishing Design
}

\author{
Yixuan Xie ${ }^{1,2}$, Ridzuan Bin Hussin ${ }^{1}$, Azlin Lryani Binti Mohd Noor ${ }^{1}$ \\ ${ }^{1}$ Faculty of Arts, Computing and Creative Industry, Universiti Pendidikan Sultan Idris, Tanjong Malim, Malaysia \\ ${ }^{2}$ School of Arts and Design, Huizhou University, Huizhou, China \\ Email: 365508782@qq.com
}

How to cite this paper: Xie, Y. X., Hussin, R. B., \& Noor, A. L. B. M. (2021). The Design Method of "Semiosis" in Interior Furnishing Design. Art and Design Review, 9, 254-262.

https://doi.org/10.4236/adr.2021.93020

Received: June 18, 2021

Accepted: July 24, 2021

Published: July 27, 2021

Copyright (c) 2021 by author(s) and Scientific Research Publishing Inc. This work is licensed under the Creative Commons Attribution International License (CC BY 4.0).

http://creativecommons.org/licenses/by/4.0/

(c) (i) Open Access

\begin{abstract}
Following the intensified trend of "jumbling together" and "crisis of feature" in interior furnishing design, there is a pressing need for design with "integrality" and "difference". In this paper, we explain the "semiosis" design method of interior furnishing design from three steps, and demonstrate its feasibility through a case study. The first step is the integration and analysis of design background information. Second, we suggest extracting the design elements in the way of abstracting form, keeping archetype, choosing typical. Finally, we propose that the design elements extracted in the first two steps should be further organized and applied in the space. The main methods include the principle of motif repetition, unification and minimalism. We conclude that these research approaches have the potential to achieve design effects such as "integrality" and "difference", and solve the issues of "jumbling together" and "crisis of feature" in interior furnishing design.
\end{abstract}

\section{Keywords}

Semiosis, Interior Furnishing Design, Design Method

\section{Introduction}

Interior furnishing design belongs to the field of interior design, in the broad sense refers to the construction and planning of spatial themes, in the narrow sense refers to the design and collocation of specific furnishings. In recent years, as a new direction of traditional interior design and an important complement, interior furnishing design has become an independent professional direction (Xie, 2018).

Semiotics is the theory par excellence of the artificial and therefore should have a substantial role in guiding design and understanding designed phenome- 
na. In the field of design, particularly in architecture, landscape and interior design studies, the semiotic approach is not unknown (Goharipour, 2019; Pereira \& Calo, 2017; Lindström et al., 2011; Lindsay Tan, 2011; Loustau, 2008). Geoffrey Broadbent (1980) argued that some architects have found one or more of the semiotic approaches of value in design generation, there is ground for believing that semiotic approaches have application throughout the whole of designing. This idea is shared by Holt (2017) in which "if the design is a signifying practice, common to all semiotic-based design theory is the search for a language, or at least a grammar, of design".

Compared with traditional architectural semiotics and environmental semiotics, the "semiosis" design method concerned in this research emphasizes the whole process of using symbols in design, which has strong dynamic characteristics. Although scholars have identified the importance of symbols for design research, the design method of "semiosis" is reflected in the interior furnishing design, which is very lacking.

\section{Problem Statement: Interior Furnishing Design in the Context of "Jumbling Together" and "Crisis of Feature"}

Due to the development of economy and the integration of social communication, design shows a general sense of convergence from the perspective of culture. The trend of "jumbling together" and "crisis of feature" have become a common problem that restricts the development of interior furnishing design.

First of all, the problems of "jumbling together" in interior furnishing design are as follows: bringing design elements together in a random way makes them lose the context in which they depend (Xie, 2017). The interior furnishing design is a discipline with a strong systemic and thematic nature. It has an urgent need for "integrated design forms". Many interior furnishing cases lack a systematic and comprehensive understanding of this basic demand, and the design elements were pieced together indiscriminately. This is the problem one.

The second, the problems of "crisis of feature" in interior furnishing design are as follows: the phenomenon of worshipping everything foreign countries and blindly pursuing internationalism is increasingly obvious (Zheng, 2018). "European style", "Mediterranean style", "Modernism" and "Southeast Asian style" has been copied over the past 20 years in China. These designs are one-sided pursuit of visual form, each design form is very similar ( $\mathrm{Hu}, 2018)$. Moreover, these designs have nothing to do with the local historical context, regional characteristics, and site environment. These so-called interior furnishing design are often blind follow the trend, or copy everything indiscriminately and transplant mechanically. This is the problem two.

\section{The Proposal of "Semiosis" Interior Furnishing Design Method}

In response to the above "jumbling together" and "crisis of feature" of interior furnishing design, how to sort out a relatively complete interior furnishing de- 
sign method, how to re-read and evaluate interior furnishing design, and how to design integrated and differentiated interior furnishing design work are worthy of our in-depth research and exploration.

In view of this, this research proposes an idea: from the perspective of "semiosis" to discuss interior furnishing design methods. The "semiosis" design method can solve the above two problems well. "Semiosis" is a simplified and pure design method, and its application will inevitably bring a high degree of unity of spatial visual effect. At the same time, different countries, nations, different times and regions have different historical contexts, natural features, and cultural forms. These elements correspond to some design symbols. Therefore, the "semiosis" design method can form strong spatial characteristics and achieve differentiated design (Hong \& Li, 2021).

\section{Discussion: The Implementation Steps of "Semiosis" Design Method in Interior Furnishing Design}

The implementation steps of "semiosis" interior furnishing design method can be divided into three steps, which are the process of integrated analysis of design background information, the process of design elements extraction and the process of space symbol formation.

\subsection{Design Background Information Integration Analysis Based on History, Culture, Regional Characteristics, and Themes}

The design process of "semiosis" interior furnishing design can be divided into the process of integrated analysis of design background information, the process of design elements extraction and the process of space symbol formation. The integrated analysis of design background information is the preparatory part of the design process, and the subsequent design elements extraction is also based on this. The design background information can be roughly divided into four categories: history, culture, regional characteristics and themes. No matter who the designer is, and whether designing a hotel, a club, or a small apartment, the above information must be considered one by one before designing (Shema, 2019).

\subsection{Design Elements Extraction}

The extraction of design elements in interior furnishing design is a general summary and refinement of the history, culture, regional characteristics and theme of the design site, which is the second step of "semiosis" of interior furnishing design, and also a crucial step. Whether the result of design elements extraction is correct or not and the degree of good or bad will have a direct influence on the formation of spatial symbols. The extraction of design elements is by no means a simple imitation and copying. In this research, the methods and principles of design elements extraction in interior furnishing design are summarized as follows. 


\subsubsection{Abstract Form}

The abstract form is to use a simplified method to refine the object image, break the integrity of the object image, and achieve the purpose of abstract extraction of design elements. In the essence of abstraction, it is only a formal method, not an end. The abstract form is actually a special use of the figurative form. The figurative form is gradually simplified and refined into a more abstract form, and there is a certain similarity between the figurative form and the abstract form. For example, geometric shapes are derived from natural shapes and gradually extracted. Among them, the Egyptian pyramid is an excellent example. The Egyptian pyramids were originally designed to imitate a hill, but the hills were abstracted into a square cone. Another example was the Omotesando Prada flagship store in Japan, which consists of countless diamond-shaped glass frames. The inspiration for this design came from the abstraction of the crystal, and the diamond was extracted from the crystal as a design element.

\subsubsection{Keep Archetype}

Referring to the concept of "archetype", we have to mention the famous Swiss psychologist Carl Gustav Jung. "Among the concepts commonly associated with C.G. Jung, few are more widely recognized, nor more poorly understood, than the theory of archetypes". Jung defined archetype as "the long-term accumulation of the universal psychological experience of generations of human beings", which is the collective unconscious reaction of human beings. It can touch the most primitive emotions in the depths of human consciousness.

The "archetype" itself has strong symbolic characteristics. One of the most important points of the influence of archetype theory on interior furnishing design is its "gene" function. "Archetype" carries the national memory and original experience of human beings, and it contains generalized emotions, so the retention of "archetype" is crucial in the process of symbol extraction.

The list of examples of using "archetype" for design is endless. Marcus Vitruvius Pollio's "The Ten Books on Architecture" infers the origins of the three pillars of ancient Greece. He believes that the Doric column is intentionally based on the male figure, the Collins column is based on the girl figure, and the Ioni column is based on the strong woman figure ( $\mathrm{Zhu}, 2009)$. In his book "Discussion on Architecture", M. A. Laugier proposed that the original hut was the archetype of all the magnificent buildings. Vertical branches remind us of pillars; the horizontal branches remind us of the cornice on the top of a column; the top of the intersection gives us the inspiration of the gable wall (Figure 1). In addition, Schroder House designed by Gerrit Thomas Rietveld can be seen as a three-dimensional Piet Cornelies Mondrian's painting (Figure 2(a), Figure 2(b)). These are the results of the archetype design adopted by the designer (Broadbent, 1980).

\subsubsection{Choose Typical}

Typicality is put forward on the basis of category problem, it is the representative thing that can fully show the characteristic of this category in a certain category. 


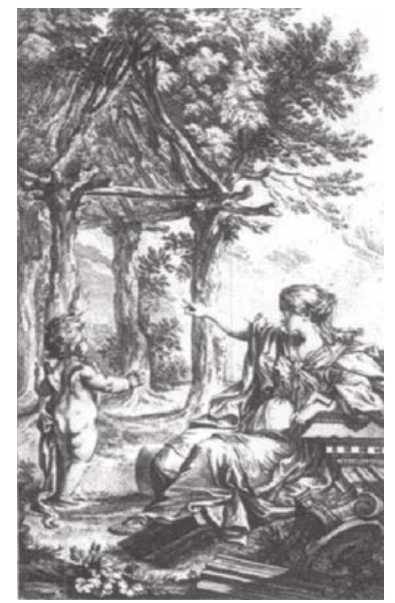

Figure 1. The original hut that M. A. Laugier said.

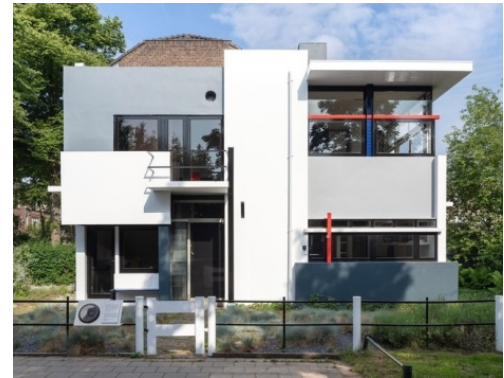

(a)

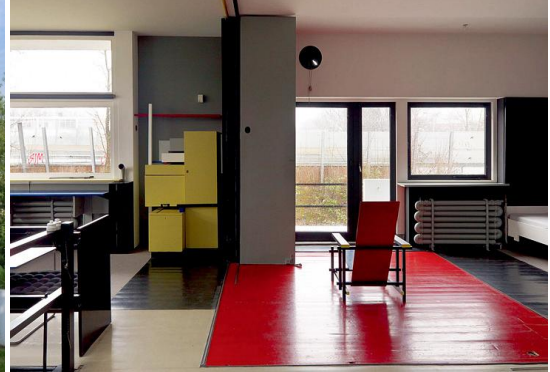

(b)

Figure 2. (a), (b) schroder house.

The key of choosing typical of symbol extraction method lies in a purposeful choice. Sort out the typical components of a conceptual category from non-typical components, so as to get the most representative and cognitive value of this category, and to achieve the purpose of recognizing a whole category through this typical symbol.

Looking at the design of hotels around the world, Aman Hotel Group has applied the "typicality" approach to an extremely sophisticated level. As a leader in luxury hotels, Aman Hotel Group's "one shop, one view" design concept has long been a benchmark in its industry. Each Aman Hotel design is fully integrated with local characteristics, that is, the full use of cultural and regional models. Staying in any Aman Hotel in the world, you can enjoy the essence of the local characteristics. From Aman Summer Palace Hotel, to Aman Dayan Hotel, the "typical" approach is most vividly reflected (Figure 3, Figure 4). Aman Summer Palace Hotel is only a few steps away from the East Gate of the Summer Palace. The designer renovated the century-old house in the resort according to the style of the Ming and Qing palaces in China. This will truly reproduce the private residence life of the royal family a hundred years ago. Aman Dayan Hotel is located on the top of Lion Rock, overlooking the winding streets and rivers of the ancient town of Lijiang. It follows the architectural style of the nationality and feels the tranquility of life in exquisite wooden buildings. 


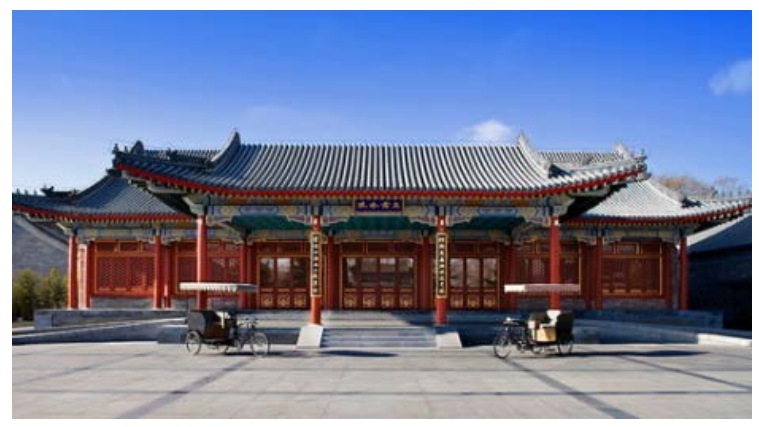

Figure 3. Aman summer palace hotel, Beijing.

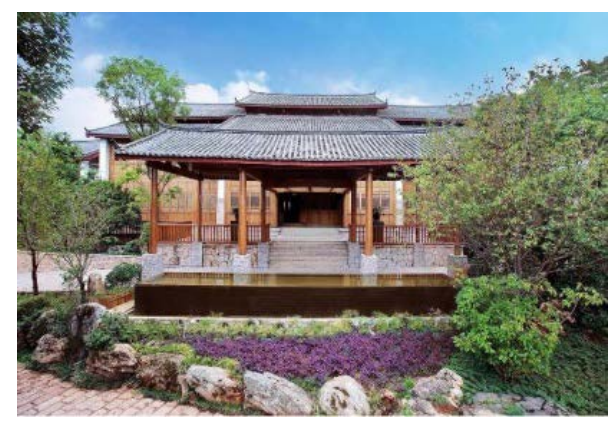

Figure 4. Aman dayan hotel, Lijiang.

\subsection{The Formation of Space Symbols}

The core of the design is the construction of its "symbol system". Substantially, it can be talked about the design process is the process of symbol construction. This idea is shared by Parsaee, Parva \& Karimi (2015) in which "consider design as a language that is created by a system of signs".

After the above two steps (integrated analysis of design background information and design elements extraction), one or several design elements obtained can be used as symbols for interior furnishing design. These design elements are like the language of space, conveying the spiritual connotation, times and cultural information behind the design. The further organization and use of these design elements makes it a true "design symbol". In the context of "semiosis", we try to generalize the inherent regularity of design elements organization, mainly as follows: motif repetition, unification, and Minimalism.

\subsubsection{Motif Repetition}

Motif repetition is the most basic method of design element organization, and it is also an important means of space symbol formation. This repetition is not the exact same to be copied, it can be a repetition of the motif. In actual design, we make a detailed analysis of the history, culture and theme concepts of the design site, extract one or several elements from them, and use this as a symbol to apply to the interior furnishing design through the motif repetition. Because the same symbol form is used in the design, the visual effect of using the symbol to lead the space is formed, and the "semiosis" interior furnishing design effect also appears. 
The use of motif repetition in design has a long history. The helmet roof (onion roof) in the Byzantine architecture and the gold glazed roof with red walls and columns in the ancient Chinese palace architecture are all in the way of motif repetition, forming strong "semiosis" images respectively. In contemporary, designers often adopt this approach to form "semiosis" design. When talking about the Beijing Xiangshan Hotel, people will think of the repeated use of squares and circles in the space: square gates, windows, wall lamps, floor coverings, round moon-shaped doors, tables and chairs, etc. The square and circle are cleverly combined in a space. Such a design effect is obviously thoughtful, which hides the designer's intention-the formation of "semiosis" design based on the motif repetition approach. In addition to the Beijing Xiangshan Hotel, this approach has been well embodied in the Suzhou Museum, China, the Eastwing of National Gallery, Washington D.C., and the Bank of China Tower, Hong Kong.

\subsubsection{Unification}

Unification is the basic principle of any kind of design, and of course it is also the basis for the formation of spatial symbols in interior furnishing design. The principle of unification refers to the consistency of the use of elements, and its deep core refers to the consistency of the use of rules. The principle of uniformity in interior furnishing design includes the unity of color elements, and spatial color rules, shapes and patterns elements, and spatial shapes and patterns rules, as well as the uniformity of material elements and spatial material rules. Only by following the principle of unification can we connect the furnishings of different forms and functions into an organic whole, so as to create the iconic space and realize the "semiosis" design.

The use of elements under the guidance of the unity principle prevents the whole being replaced by parts from the overall perspective, which emphasizes the coordination of the combination of elements. Select the most representative elements as the raw materials for design from various aspects such as history, culture, region and theme. It is better to be less and refined. The most taboo is the "jumbling together" of elements, which seems to be everything, but in fact it is a mess.

\subsubsection{Minimalism}

Minimalism, that is, the pursuit of "less" and the simplicity of spatial form. The principle of minimalism described in this research is for the purpose of forming an overall spatial connection. Minimalism is a concept about using the number of elements. It is not an absolute quantitative concept, but includes the meaning of "relative". The principle of minimalism does not mean the absolute singleness of the number of elements used, nor does it mean a complete denial of other elements, but only emphasizes the prominence of a certain type of element. Taking one of the most prominent elements as the focus of this design is within the scope of the principle of minimalism. For the repeated use of this element in space, it belongs to the scope of the principle of motif repetition and unification. 


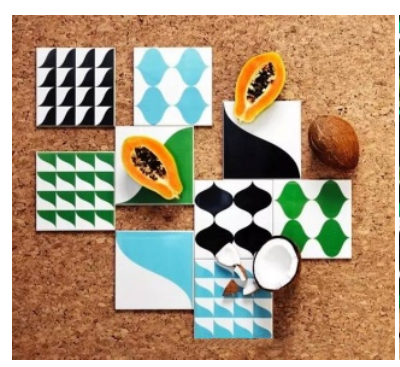

(a)

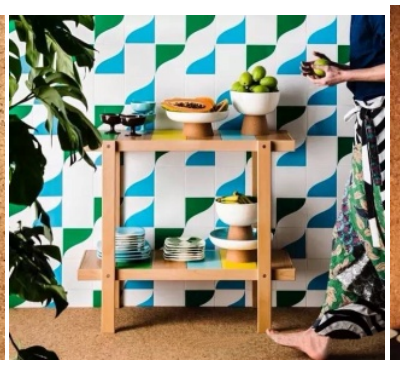

(b)

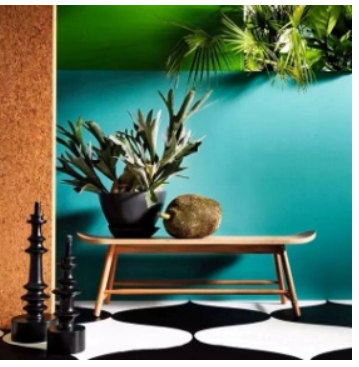

(c)

Figure 5. (a)-(c) 2016 IKEA new product furnishing case.

The 2016 IKEA new product furnishing case integrates a variety of design elements, color, shape and pattern are defined. These designs seem to break the principle of minimalism. But it's not. In fact, the expression of the principle of minimalism in the 2016 IKEA new product furnishings case has risen to the level of the theme. The theme is defined as tropical Brazil. Brazil has a typical tropical rainforest style. The most typical elements of the tropics are dark green vegetation, vast sky, abundant fruits, broad-leaved plants, large parrots, coconuts, papayas, jackfruit, etc. This series of new products are designed around these elements closely (Figures 5(a)-(c)). As a result, when people talk about 2016 IKEA new products, they will think of "tropical Brazil". Tropical Brazil has become a synonym for 2016 IKEA new products, and "symbolization" is thus formed.

\section{Conclusion}

In the process of "semiosis" design, the formation of spatial symbols will inevitably bring about "integral" and "characteristic" spatial effects. The "semiosis" design here is not only a design method, but also a design concept and a design evaluation angle.

Compared with the static presentation of symbol theory, "semiosis" emphasizes the dynamic process of using symbol theory for specific design. From the perspective of "semiosis", this research chose the symbol theory can clearly display the design process and the most instructive part of the interior furnishing design, from the integration analysis of design background information, the extraction of design elements, and formation of spatial symbols these three aspects to research "semiosis" interior furnishing design method. It is true that interior furnishing design is a complex process in which various design factors and various kinds of relevant design information influencing each other. The principles of symbol extraction are also varied. This research only focuses on the most representative aspects to analyze.

\section{Conflicts of Interest}

The authors declare no conflicts of interest regarding the publication of this paper. 


\section{References}

Broadbent, G. (1980). Architectural Objects and Their Design as a Subject for Semiotic Studies. Design Studies, 1, 207-216. https://doi.org/10.1016/0142-694X(80)90005-8

Goharipour, H. (2019). Narratives of a Lost Space: A Semiotic Analysis of Central Courtyards in Iranian Cinema. Frontiers of Architectural Research, 8, 164-174. https://doi.org/10.1016/j.foar.2019.01.004

Holt, M. (2017). Semiotics and Design: Towards an Aesthetics of the Artificial. The Design Journal, 20, S332-S341. https://doi.org/10.1080/14606925.2017.1352860

Hong, T. A., \& Li, Q. (2021). Research on Symbolic Design Concept and Practice of Intelligent Furniture. China Forest Products Industry, 58, 95-97.

Hu, X. C. (2018). The Application Research of Regional Symbols in the Environmental Design of Urban Cultural and Creative Park. Design, 11, 13-15.

Lindsay Tan, M. F. A. (2011). A Review of Environmental Symbology: Origins and Contributions toward a Theoretical Framework. Journal of Interior Design, 36, 39-49. https://doi.org/10.1111/j.1939-1668.2011.01056.x

Lindström, K., Kull, K., \& Palang, H. (2011). Semiotic Study of Landscapes: An Overview from Semiology to Ecosemiotics. Sign Systems Studies, 39, 12-36. https://doi.org/10.12697/SSS.2011.39.2-4.02

Loustau, J. (2008). A Theoretical Base for Interior Design: A Review of Four Approaches from Related Fields. Journal of Interior Design, 14, 3-8. https://doi.org/10.1111/j.1939-1668.1988.tb00114.x

Parsaee, M., Parva, M., \& Karimi, B. (2015). Space and Place Concepts Analysis Based on Semiology Approach in Residential Architecture. HBRC Journal, 11, 368-383. https://doi.org/10.1016/j.hbrcj.2014.07.001

Pereira, G., \& Calo, S. (2017). The Semio-Pragmatics of Architecture. Architectural Theory Review, 21, 62-72. https://doi.org/10.1080/13264826.2016.1270341

Shema, A.I. (2019). Rethinking Architecture and Urban Form in the Context of Power Discourse: Case Study Nicosia, North Cyprus. Journal of Asian and African Studies, 54, 1227-1246. https://doi.org/10.1177/0021909619865570

Xie, Y. X. (2017). Explore the Function of Symbol in Interior Furnishing Design. Design, 1, 48-49.

Xie, Y. X. (2018). Interior Furnishing Design Curriculum Reform Based on Theme Perspective. Art Education Research, 21, 114-115.

Zheng, G. (2018). Research on Chinese Interior Art Design Style, Proceedings of 2018 4th International Conference on Education, Management and Information Technology (ICEMIT 2018). Francis Academic Press, 607-610.

Zhu, X. C. (2009). Prototype Ideas in Western Architecture Theories. Huazhong Architecture, 27, 39-41. 